REFLECTIONS:

NEUROLOGY AND

THE HUMANITIES

Section Editor

Anne W. McCammon,

MD, FAAN

\title{
The rest of the iceberg
}

Diane G. Cook, BA*

Kirk W. Hall, MBA*

Linda L. Hall, BS*

Terri A. Schmidt, MD, MS*

Malenna A. Sumrall, $\mathrm{PhD*}$

Keiran K. Tuck, MBBS

Correspondence to

Dr. Tuck:

keiran_tuck@hotmail.com
The easily recognizable motor symptoms of Parkinson disease (PD) are just the tip of the iceberg. Beneath the surface lurk over 20 nonmotor symptoms ranging from nuisance to life-threatening. As anyone familiar with the fate of the Titanic can tell you, these are game changers.

At the Second Annual International Palliative Care in PD Working Group in 2016, we, who are people with PD (PwPD), and our care partners, were asked to share our experiences with nonmotor symptoms. These stories are adapted from our talks and provide a window into how nonmotor symptoms affect our lives.

\section{DIANE}

10 PM: It's dark, inside and outside. Most people are asleep. I'm not. I have already taken mirtazapine and melatonin. I'm trying to sleep but my skin itches. I get up and rub on some Benadryl. It usually doesn't work, but I try it anyway. Eventually, I doze off and sleep fitfully.

Midnight: I'm awake. I just can't get comfortable. I'm too cold. I'm too hot. I toss the covers off. My legs have that creepy, crawly, jittery sensation. I get up and walk around the house. After a while I go back to bed.

2 AM: Painful shoulders and hips wake me up. Then I realize my stomach hurts. I go to the kitchen and eat some cheese. That helps me go back to sleep.

3 AM: I hear my husband telling me to stop shouting and to please turn over. I was having one of those terrifying dreams. I turn slowly because I am so achy and stiff. I try to continue sleeping.

4 AM: I get up to go to the bathroom. Sometimes I just stay up. It is less of a struggle to stay up than to try to get back to sleep. I am never sure how much rest my body has gotten. I worry about the physical and cognitive effects of lack of sleep.

5 AM: Gas and flatulence await me as I wake up and begin to move in bed. I drink 2 cups of Miralax, hoping that today I will have a bowel movement. Mylanta is my constant companion. I have been to see 4 specialists over 10 years and still have no relief from intermittent constipation, cramping, diarrhea, bloating, and gas. If I am constipated for 4-5 days, I become physically ill, overcome by lightheadedness, nausea, and weakness, sometimes to the point that I cannot drive. In pursuit of relief, I have drastically restricted my diet so I no longer eat most of the foods I enjoy. In fact, there are far more foods I can't eat than I can. I am now underweight.

9 PM: The day is over. I again take mirtazapine and melatonin to help me sleep. I take Zantac for my stomach. And I hope, perhaps tonight, each time I wake up, somehow I will be able to roll over and go back to sleep.

\section{KIRK}

Cognition issues began soon after my diagnosis with PD and have since been my biggest concern. When I tried to learn more, I encountered resistance to open discussion of cognitive changes by doctors and patients, as well as lack of information online. However, it did not take long for me to realize that a significant percentage of PwPD have cognitive changes and eventually develop dementia that is a terminal condition. This news would get most people's attention and I was no exception. In the 8 years since my PD diagnosis, I have developed mild cognitive impairment (MCI). As MCI increases the risk of dementia, I committed to being transparent about the effect this had on my life and hoped to encourage open discussion of this subject. My book, Window of Opportunity, shared information designed to expand the conversation, outlined scientific ideas and thoughts regarding causation, and discussed implications for the future. My own experiences in this prodromal time period have enabled me to continue to live well and productively. Now I have reached acceptance of whatever the outcome may be. My goals are to learn from the past, plan for the future, and live in the moment; focus on quality of life; remain engaged as long as possible; and finish the race well.

\section{LINDA}

Through 47 years of marriage, my husband and I experienced many life events (jobs, children, relocations, surgeries) that resulted in "planned" relationship role changes. However, my current role as care

*These authors contributed equally to this work.

Listen to Dr. Tuck read this story, available on the $\mathrm{iPad}^{\circledR}$ and Android ${ }^{\mathrm{TM}}$ devices. 
partner of a PwPD and MCI involves not only planned role changes but also role shifting. Just like driving a car with manual transmission, our daily lives shift from one gear to another: up, down, neutral, and don't forget reverse! MCI has changed my husband's focus, attention, and concentration. His problem-solving and multitasking skills have declined. As these deficits fluctuate throughout the hours and days, we must shift, and it is not automatic. We use an updated daily planner/calendar, limit activity options, and assure I have his undivided attention.

Then, there's driving. Years ago, when traveling to Colorado, my husband would drive all the way there. Returning home, we would share the driving time. As years have passed, my husband's ability to multitask, concentrate, and focus have diminished, making driving in the fast lane a challenge. PD slows everything! Thus, we have had to downshift and change pace. I now do most of the driving, with my husband driving occasionally in areas of minimal traffic or when we are close to home, where there are fewer distractions. We are now living our lives in second gear. For now, we have not yet shifted to first gear, where I do all the driving.

The fluctuations and role shifting affect many areas of our daily life. We have found that effective and sensitive communication helps keep us on course. And don't forget the benefits of a good sense of humor and lots of laughter. Yes-having PD/MCI is often like driving a car with a manual transmission. Rev up your engines and cherish the journey.

\section{MALENNA}

Mood and motivation disorders are among the most challenging nonmotor symptoms to diagnose accurately in PD. Depression, a mood disorder, and apathy, a motivation disorder, have distinct characteristics, but they also have characteristics in common. ${ }^{1}$ Someone who is depressed might benefit from antidepressants; therefore, being diagnosed as apathetic could deprive such a person of needed medication. On the flip side, someone who is apathetic but is diagnosed as depressed might be prescribed unnecessary and possibly harmful medication. ${ }^{2}$

My husband was a strong, confident PwPD. He was prescribed antidepressants for depression, but I was never convinced he was depressed. His diagnosis was based on interaction during a doctor's visit, not a screening scale. So I wonder if there was miscommunication between us and the doctor about mood vs motivation. Yes, he felt the loss that PD had caused him, but he still enjoyed life. Joy and happiness shone on his face until the end.

In spite of being a care partner who was always on the Internet looking for answers, I only discovered apathy as a symptom late in my husband's life. Neurologists have only a short time every few months with the patient. Between those visits, the patient and care partner make many observations. I wish that we had been given better information and guidance about how to communicate his symptoms to his doctor. Good communication is absolutely crucial when it comes to PD nonmotor symptoms. My husband was likely apathetic, not depressed. The thought that he might have been made worse by years of antidepressants is very hard to live with.

\section{TERRI}

I do not talk about PD, because PD is not the most important part of me. I would rather talk about my grandkids, my family, my friends, my adventures and travels, my years as an emergency and now palliative care physician. However, it is important for health professionals to have some understanding of what it feels like on the inside. Therefore, here are the top 10 things I hate about PD.

\section{0: Is it me or PD?}

Is my decision to eat a second piece of cake my old love of sweets or the effect of dopamine on the reward system? I do not like that the disease might change my personality.

\section{9: Unpredictability.}

Despite taking medications on time, exercising, and getting sleep and rest, I cannot predict and know how a day will unfold.

8: Internal weird, hard to describe feelings.

I often do not feel right on the inside. The right and left sides of my body can feel different sizes. I often see, think, and feel through a fog of pea soup.

7: Knowing this is the best things will get.

It is difficult to come to grips with the meaning of the words "chronic, progressive, neurologic disease."

6: My grandkids will remember me for things I could not do.

"Be careful of grandma... she can't do that." My wonderful is defined by what I can do, not what I cannot do. I traveled around the world, rafted class 5 rivers, climbed mountains, motorcycled across the continent, and rappelled into crevasses. I like to see myself as the glittering, magical, fairy grandmother but what will my grandkids remember? That I move slowly? Cannot do the things others in the family do? My expression is dull?

\section{5: Everything is work.}

It is harder to do things others take for granted. When I get out of the car, I pause, think for a moment, "turn, put your feet on the ground, put your hand on the door post, stand up...." Nothing is automatic. 
4: I hate asking for help.

I am a caregiver. First as a lifeguard, then as a nurse, now as a physician. PD takes me out of that role. I am the one who runs to, not away from, the fire, the disaster. Now, I have to rely more and more on others. I do not like it, and want to scream, "I can do it myself?"- -but I cannot.

3: I am often not excited to get up.

I am not depressed. I wake up comfortable and relaxed for a moment, but I do not want to start the day because the stiffness, pain, and headaches start. It would be nice to wake up, get out of bed, and feel good.

2: My biggest fear...that I will lose my mind.

My grandfather had Alzheimer disease, as did my mother. Now, there is a strong likelihood that I will develop dementia related to PD. This scares me. I hope when it happens I have associated apathy and do not care. I hope that I do not know that I am a demented old lady. I hope it does not happen to me. I would rather go out with a bang than a whimper.

1: It is not the motor stuff; it's the other stuff.

I am fatigued. It is work to do everything. I often cannot fall asleep (unless I cannot stay awake) and once asleep cannot stay asleep. If I stay asleep too long, I get stiff, so I have to set an alarm to wake up and take meds. Fatigue and insomnia make the best of us foggy. Add to that the slowness of PD and the side effects of the various medications and I am back to thinking through a fog or swimming in pea soup. My mouth is dry, the corners of my mouth are wet, my eyes are dry, my eyes water, my toes spasm, I have hot flashes, I get orthostatic, my head hurts, my neck hurts...the little things add up. None of them is a big deal alone but together they make it hard to forget about that chronic, progressive neurologic disease. Even when you cannot see it on the outside and my symptoms seem under control, I can feel it on the inside and it does not go away. Please remember that.

\section{ACKNOWLEDGMENT}

The authors thank Benzi Kluger, MD, for the initial idea, and the Parkinson's Disease Foundation for funding the Palliative Care in PD Working Group.

\section{REFERENCES}

1. Den Brok M, van Dalen JW, van Gool WA, et al. Apathy in Parkinson's disease: a systematic review and meta-analysis. Mov Disord 2015;30:759-769.

2. Zahodne LB, Bernal-Pacheco O, Bowers D, et al. Are selective serotonin reuptake inhibitors associated with greater apathy in Parkinson's disease? J Neuropsychiatry Clin Neurosci 2012;24:326-330. 


\title{
Neurology
}

\author{
The rest of the iceberg \\ Diane G. Cook, Kirk W. Hall, Linda L. Hall, et al. \\ Neurology 2017;89;e254-e256 \\ DOI 10.1212/WNL.0000000000004682
}

This information is current as of November 27, 2017

\section{Updated Information \&} Services

\section{References}

Subspecialty Collections

Permissions \& Licensing

Reprints including high resolution figures, can be found at: http://n.neurology.org/content/89/22/e254.full

This article cites 2 articles, 0 of which you can access for free at: http://n.neurology.org/content/89/22/e254.full\#ref-list-1

This article, along with others on similar topics, appears in the following collection(s):

Parkinson's disease/Parkinsonism

http://n.neurology.org/cgi/collection/parkinsons_disease_parkinsonism

Information about reproducing this article in parts (figures,tables) or in its entirety can be found online at:

http://www.neurology.org/about/about_the_journal\#permissions

Information about ordering reprints can be found online:

http://n.neurology.org/subscribers/advertise

Neurology ${ }^{\circledR}$ is the official journal of the American Academy of Neurology. Published continuously since 1951, it is now a weekly with 48 issues per year. Copyright @ 2017 American Academy of Neurology. All rights reserved. Print ISSN: 0028-3878. Online ISSN: 1526-632X.

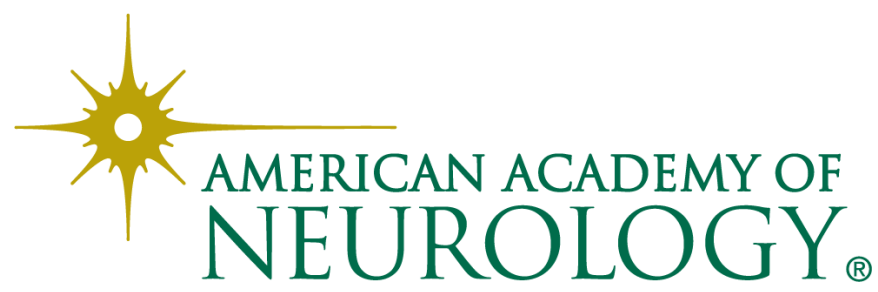

